\title{
Determination of Fatigue Limit of Coir/CNT/Fly Ash Reinforced Epoxy Polymer Matrix Composite
}

\author{
Venkatachalam Gopalan*, Pradhyumn Bhardwaj', Nilesh Satonkar ${ }^{1}$, Vignesh Pragasam \\ 1 School of Mechanical Engineering, Vellore Institute of Technology, Chennai Campus, Vandalur-Kelambakkam Road, \\ Chennai 600127, India \\ * Corresponding author, e-mail: g.venkatachalam@vit.ac.in
}

Received: 13 April 2020, Accepted: 08 June 2020, Published online: 22 July 2020

\begin{abstract}
In the quest of new material development, polymer matrix composite plays prominent role. Instead of reinforcing synthetic material in the polymer composite, an attempt is made in this work to reinforce green/recyclable/reusable materials in the polymer composite. Composite specimens are made with epoxy as matrix and coir/CNT/fly ash as reinforcements. The influences of wt.\% of coir/CNT/fly ash on fatigue behavior of composite are determined. Response Surface Methodology (RSM), a Design of Experiments (DOE) approach is followed in specimen preparation and testing. ANOVA is used to find the influences of different parameters such as wt.\% of coir/ CNT/fly ash on fatigue behavior of composite. Optimized levels of parameters are also found out.
\end{abstract}

Keywords

polymer matrix composite, fatigue limit, Response Surface Methodology, Design of Experiments

\section{Introduction}

Increase in the innovation during the time of world wars in past century led us to the daunting situation in the present like increase in the amount of non-recyclable plastics on land and water murdering the flora and fauna, polluting every source of energy. Material like plastic or composite is needed which can fulfill our demands and that is also perishable in the environment without leaving hazardous waste. Consequently natural fibers come into the picture. These fibers are very ubiquitous to use that comes with economical cost, low density, environment friendly nature and $\mathrm{CO}_{2}$ neutrality. These natural fiber composites can be used in distinct area where deduction in weight is highly required keeping ecology in mind.

Many investigations/studies are reported in the literature about use of Coir, Carbon Nano Tubes, Fly Ash and Sisal as reinforcements in polymer matrix composites. Coconut Fiber (Coir) is a natural fiber obtained from the outer covering of coconut. The coir fiber is relatively waterproof, and is one of the few natural fibers which offer resistant to damage by saltwater. The coir fiber is elastic enough to twist without breaking and it holds a curl as though permanently waved. Pandi et al. [1] concluded that the use of coir in the concrete increases compressive strength and split tensile strength as compared to the conventional concrete. Ali and Chouw [2] studied the viability of using coconut-fiber ropes as vertical reinforcement in mortar-free low cost housing in earth quake prone regions. The study concluded that the pull out energy increases with an increase in embedment length, rope diameter, cement and fiber content in the matrix. Ali et al. [3] studied the influences of $1 \%, 2 \%, 3 \%$ and $5 \%$ fiber contents at fiber lengths of $2.5,5$ and $7.5 \mathrm{~cm}$ on properties of concrete. For a proper analysis, the properties of plain cement concrete were used as reference by Ali et al. [3]. It was seen that damping of coir fiber reinforced concrete (CFRC) beams increases with the increase in fiber content. It was observed that CFRC with a fiber length of $5 \mathrm{~cm}$ and fiber content of $5 \%$ produced the best results. Yousif and $\mathrm{Ku}$ [4] demonstrated the existence of high interfacial adhesion characteristics between coir fiber and polyester resin and hence proved the suitability of using such composites as liquid storage tanks. Karthikeyan and Balamurugan [5] concluded from their investigations that epoxy composite reinforced with coir fiber of length $30 \mathrm{~mm}$ shows better impact strength than other lengths. They also concluded that there is no significant increase in impact strength of alkali treated composite if the alkali concentrations exceed $6 \%$. Fu et al. [6] studied the elastic modulus of 
hybrid particle/short fiber reinforced polymer matrix composites theoretically by considering the effects of absolute and relative reinforcement volume fractions, fiber elastic modulus, particle modulus, fiber length and orientation.

Bansal et al. [7] compared bamboo - jute polymer composite with bamboo - coir polymer composite pertaining to impact strength and hardness. Authors concluded that bamboo-coir epoxy polymer composite shows better results in impact strength and hardness when compared to the other two composites i.e. bamboo epoxy polymer composite and bamboo-jute epoxy polymer composite. Basiji et al. [8] dealt with the effect of fibre length and fibre loading level on modulus of rigidity, modulus of elasticity, tensile strength and impact strength. Ramesh et al. [9] found that the combination of banana fibre and epoxy resin in polymer matrix composite exhibits maximum result for both tensile strength and flexural strength. Hossain et al. [10] studied jute epoxy laminated composite and concluded that in longitudinal direction, tensile strength and stiffness are higher but found opposite in the transverse direction. Saradava et al. [11] improved the mechanical properties of coir fiber reinforced polymer composite by using red mud as the filler.

Banerjee et al. [12] predicted the stress analysis of a single walled carbon nano tube using finite element method and also analyzed the changes in Young's modulus and thickness for the 3 phased composites. Ashrafi et al. [13] found few advantages like impact area reduction, increase in impact strength, mode I fracture toughness and mode II inter laminar fracture toughness with the addition of $0.1 \%$ of single walled carbon nano tube in epoxy. Yokozeki et al. [14] performed investigations on carbon fiber reinforced polymer composites with (5 wt.\%) and without cup stacked carbon nano tubes (CSCNT) and quasi-isotropic laminates (with 0, 5 and $10 \mathrm{wt} . \%$ of CSCNT in epoxy) and found improvement of several properties and no adverse effects on mechanical properties due to cup stacked carbon nano tubes.

Fly ash is a waste product obtained from burning coal mainly in thermal power plant. It has awful effects on health of environment that's the reason reuse of fly ash is very important. Patil et al. [15] found that fly ash can be used in the small amount as an additive which improves the compressive strength of the concrete. Chen et al. [16] demonstrated that fly ash reinforced epoxy polymer composites with $15 \%$ of fly ash exhibited significant improvement in impact strength, flexural strength and flexural modulus. They also concluded that the addition of fly ash in epoxy polymer composites also resists crack propagation and improves fracture toughness. Deepthi et al. [17] reinforced fly ash cenospheres with high-density polyethylene to make lightweight composites to reduce weight, shrinkage, and water absorption. The result showed that there is a remarkable improvement in the mechanical and thermal stabilities of the composites. Nath et al. [18] experimented with unmodified and modified fly ash (surface of fly ash treated with sodium lauryl sulphate (SLS)) in the fabrication of composites with polyvinyl alcohol as matrix. The surface, modified with SLS, improved the tensile strength of the composites up to $33 \%$ and $75 \%$ higher than the unmodified fly ash. The study also proved that fly ash could be used to develop high performance biodegradable composites. Mahalingam et al. [19] investigated shear strength of $\mathrm{CNT} /$ coir/fly ash reinforced epoxy polymer composites. They arrived optimum combinations of CNT/ coir/fly ash in composites to get maximum shear strength.

Purohit et al. [20] added fly ash as the filler in polymer composite to study tensile, flexural and impact strengths. Authors concluded that addition of fly ash increases the flexural strength up to $4 \%$ fly ash in composites. Kumre et al. [21] concluded that addition of sisal fiber improves the mechanical properties in glass fiber reinforced polymer composites. Sunkara et al. [22] prepared polymer matrix composite with Nano fly ash as the filler which resulted in increase in tensile and impact strengths of the composite. D'Souza et al. [23] reviewed the mechanical properties of glass-epoxy composite with fly ash as the filler material. Authors concluded that tensile strength of composite reached to maximum of $77.2 \mathrm{MPa}$ at $6 \%$ fly ash. Also the specimen with $3 \%$ filler has the least water absorption percentage compared to $6 \%$ and $9 \%$ filler. They also observed that specimen with $9 \%$ fly ash filler has the maximum bending strength compared with $3 \%$ and $6 \%$ fly ash filler.

Akhil and Reddy [24] concluded that the mechanical strength of glass fiber reinforced polymer composite is increased by adding coal ash and fly ash powder as the filler material. Pattanaik et al. [25] studied dry sliding wear behavior of epoxy fly ash composite with the help of Taguchi method of design of experiment. Authors investigated that with least number of experiments, Taguchi L32 orthogonal array gives the most accurate result. Tiwari et al. [26] studied the mechanical and thermal properties of fly ash/epoxy composite and observed that even small content of nanofiller reduces the defects between fillers and polymer interface and enhances the mechanical properties of the composite. Singla and Chawla [27] concluded that by adding 
fly ash in epoxy composite, the compressive strength can be increased. Ramakrishna et al. [28] analyzed that the tensile and damping properties of glass fiber epoxy composites are improved by adding $5 \%$ fly ash as the filler. Mohan et al. [29] studied the mechanical properties of fly ash filled glass fiber reinforced polymer composite. The authors concluded that by addition of $2 \%$ of fly ash in composite gives better strength than that of $5 \%$ fly ash.

There are attempts reported in the literature regarding the reinforcements of CNT, coir and fly ash in epoxy polymer matrix composites separately or together. There are no attempts reported regarding the calculation of fatigue limit of such composites. The concept of fatigue limit for metallic substances has been known for many years but the limit of resources and the fight to make everything better open a new aspect for the of fatigue limit for the composite materials. Hence calculation of fatigue limit of CNT/coir/fly ash reinforced epoxy polymer matrix composite is tried in this work.

\section{Methodology}

In this work, material properties found by Venkatachalam et al. [30] are used to calculate fatigue limit. Polymer matrix composite is made with epoxy resin [LY556] as matrix and Coir fiber (in powder form)/CNT/fly ash as reinforcements. Samples are prepared based on Response Surface Methodology (RSM), a Design of Experiments (DOE) tool. The Central Composite Design (CCD) in RSM is used to arrive the different combinations of samples. The input parameters are wt.\% of coir, CNT and fly ash. Table 1 shows that wt.\% of coir and fly ash are from $0 \%$ to $2 \%$ and that of CNT is from $0 \%$ to $1 \%$. The different levels of wt.\% and its actual values are given in Table 2 .

Table 3 shows the values of yield stress in MPa taken from Venkatachalam et al. [30]. Fatigue limit is calculated using Soderberg's equation based on yield stress value.

Table 1 Different levels and wt.\% of Coir, CNT and Fly ash [30]

\begin{tabular}{|c|c|c|c|c|c|c|c|}
\hline Variables & Parameters & Levels & -2 & -1 & 0 & 1 & 2 \\
\hline A & Coir & wt. $\%$ of materials & $0(0)$ & $0.5(0.09)$ & $1(0.182)$ & $1.5(0.273)$ & $2(0.364)$ \\
\hline B & $\mathrm{CNT}$ & in composite & $0(0)$ & $0.25(0.045)$ & $0.5(0.091)$ & $0.75(0.136)$ & $1(0.182)$ \\
\hline $\mathrm{C}$ & Fly-ash & $\begin{array}{l}\text { (actual wt. in gram is } \\
\text { given in bracket) }\end{array}$ & $0(0)$ & $0.5(0.091)$ & $1(0.182)$ & $1.5(0.273)$ & $2(0.364)$ \\
\hline
\end{tabular}

Table 2 Different combinations of Tensile test specimens based on CCD of RSM [30]

\begin{tabular}{|c|c|c|c|c|c|c|}
\hline \multirow{2}{*}{ Exp. No. } & \multicolumn{2}{|c|}{ Coir } & \multicolumn{2}{|c|}{$\mathrm{CNT}$} & \multicolumn{2}{|c|}{ Fly-Ash } \\
\hline & Coded & Actual & Coded & Actual & Coded & Actual \\
\hline 1 & -1 & 0.091 & 1 & 0.1365 & -1 & 0.091 \\
\hline 2 & 0 & 0.182 & 0 & 0.091 & 0 & 0.182 \\
\hline 3 & 1 & 0.273 & -1 & 0.0455 & -1 & 0.091 \\
\hline 4 & 0 & 0.182 & 0 & 0.091 & 0 & 0.182 \\
\hline 5 & 1 & 0.273 & 1 & 0.1365 & 1 & 0.273 \\
\hline 6 & -1 & 0.091 & -1 & 0.0455 & 1 & 0.273 \\
\hline 7 & 0 & 0.182 & 0 & 0.091 & 0 & 0.182 \\
\hline 8 & 0 & 0.182 & 0 & 0.091 & 2 & 0.364 \\
\hline 9 & -2 & 0 & 0 & 0.091 & 0 & 0.182 \\
\hline 10 & 0 & 0.182 & 0 & 0.091 & -2 & 0 \\
\hline 11 & 0 & 0.182 & 2 & 0.182 & 0 & 0.182 \\
\hline 12 & 0 & 0.182 & -2 & 0 & 0 & 0.182 \\
\hline 13 & 2 & 0.364 & 0 & 0.091 & 0 & 0.182 \\
\hline 14 & 0 & 0.182 & 0 & 0.091 & 0 & 0.182 \\
\hline 15 & 0 & 0.182 & 0 & 0.091 & 0 & 0.182 \\
\hline 16 & 0 & 0.182 & 0 & 0.091 & 0 & 0.182 \\
\hline 17 & 1 & 0.273 & -1 & 0.0455 & 1 & 0.273 \\
\hline 18 & -1 & 0.091 & 1 & 0.1365 & 1 & 0.273 \\
\hline 19 & -1 & 0.091 & -1 & 0.0455 & -1 & 0.091 \\
\hline 20 & 1 & 0.273 & 1 & 0.1365 & -1 & 0.091 \\
\hline
\end{tabular}


Table 3 Values of Yield Stress of 20 samples [30]

\begin{tabular}{lc}
\hline Sample Number & Yield Stress \\
\hline 1 & 12.75 \\
2 & 10.86 \\
3 & 10.94 \\
4 & 10.86 \\
5 & 11.82 \\
6 & 11.42 \\
7 & 10.86 \\
8 & 11.04 \\
9 & 11.02 \\
10 & 11.17 \\
11 & 14.61 \\
12 & 13.18 \\
13 & 11.10 \\
14 & 10.86 \\
15 & 10.86 \\
16 & 10.86 \\
17 & 12.01 \\
18 & 11.55 \\
19 & 11.13 \\
20 & 12.23 \\
\hline
\end{tabular}

\section{Results and discussion}

In order to ensure more safety, Soderberg equation is chosen ahead of Goodman criterion and Gerber criterion. Soderberg equation, an equation used to quantify the interaction of mean and alternating stresses on the fatigue life of a material, is used to calculate the fatigue limit. The equation is typically presented as a linear curve of mean stress vs. alternating stress that provides the maximum number of alternating stress cycles a material will withstand before failing from fatigue. Line joining $\sigma_{y t}$ (yield strength of the material) on mean stress axis and $\sigma_{e}$ (fatigue limit of the component) on stress amplitude axis is called as Soderberg line. Based on the guidelines [31], $\sigma_{\max }$ and $\sigma_{\min }$ are considered as $80 \%$ and $40 \%$ of the yield stress respectively. Equation 1 represents Soderberg equation:

$\frac{\sigma_{m}}{\sigma_{y t}}+\frac{\sigma_{a}}{\sigma_{e}}=1$,

where

$\sigma_{m}-$ Mean Stress $=\frac{\sigma_{\max }+\sigma_{\min }}{2}$,

$\sigma_{y t}-$ Yield Stress,

$\sigma_{a}-$ Stress Amplitude $=\frac{\sigma_{\max }-\sigma_{\min }}{2}$,

$\sigma_{e}-$ Fatigue Limit,

$\sigma_{\min }-$ Minimum Stress,

$\sigma_{\max }-$ Maximum Stress.
Table 4 represents the values of fatigue limit of the different samples taken from the Table 2 and calculated using the Soderberg equation. Analysis of variance (ANOVA) is performed to find the influences of wt.\% of coir, CNT and fly ash using MINITAB software. Regression equation is obtained to know the influences of these input parameters on fatigue limit. Equation (2) is the regression equation obtained from ANOVA. Equation (2) is the $2^{\text {nd }}$ order polynomial equation. A comparison is also carried out between the fatigue limit values presented in Table 4 and fatigue limit values obtained from regression equation. Table 5 presents the comparison between fatigue limit values obtained from Soderberg equation and regression equation. The error is less than $10 \%$ except for two samples. Hence the regression model obtained from ANOVA can be used for further reference.

Fatigue Limit $=6.31606-0.41632 A-3.55513 B$

$+0.08400 C+0.09833 A \times A+6.05332 B \times B$

$+0.11833 C \times C-0.30275 A \times B$

$+0.39138 A \times C-1.48725 B \times C$

Where,

$A=$ Coir: $\%$ of coir used in the sample,

$B=\mathrm{CNT}: \%$ of CNT used in the sample,

$C=$ Fly Ash: $\%$ of fly ash used in the sample.

Table 4 Fatigue limit calculated based on Soderberg equation

\begin{tabular}{|c|c|}
\hline Sample No. & Fatigue Limit (MPa) \\
\hline 1 & 6.3745 \\
\hline 2 & 5.4323 \\
\hline 3 & 5.4681 \\
\hline 4 & 5.4323 \\
\hline 5 & 5.9082 \\
\hline 6 & 5.7123 \\
\hline 7 & 5.4323 \\
\hline 8 & 5.5216 \\
\hline 9 & 5.5122 \\
\hline 10 & 5.5847 \\
\hline 11 & 7.3035 \\
\hline 12 & 6.5919 \\
\hline 13 & 5.5478 \\
\hline 14 & 5.4323 \\
\hline 15 & 5.4323 \\
\hline 16 & 5.4323 \\
\hline 17 & 6.0050 \\
\hline 18 & 5.7745 \\
\hline 19 & 5.5662 \\
\hline 20 & 6.1174 \\
\hline
\end{tabular}


Table 5 Error analysis between calculated fatigue limit values and regression equation fatigue limit values

\begin{tabular}{|c|c|c|c|}
\hline $\begin{array}{l}\text { Sample } \\
\text { No. }\end{array}$ & $\begin{array}{c}\text { Fatigue Limit in } \mathrm{MPa} \\
\text { (calculated from } \\
\text { Soderberg eqn.) }\end{array}$ & $\begin{array}{l}\text { Fatigue Limit in } \mathrm{MPa} \\
\text { (calculated from } \\
\text { regression eqn.) }\end{array}$ & Error \% \\
\hline 1 & 6.3745 & 6.4152 & -0.64 \\
\hline 2 & 5.4323 & 5.2339 & 3.65 \\
\hline 3 & 5.4681 & 5.2204 & 4.53 \\
\hline 4 & 5.4323 & 5.2339 & 3.65 \\
\hline 5 & 5.9082 & 5.4673 & 7.46 \\
\hline 6 & 5.7123 & 5.5625 & 2.62 \\
\hline 7 & 5.4323 & 5.2339 & 3.65 \\
\hline 8 & 5.5216 & 5.1249 & 7.18 \\
\hline 9 & 5.5122 & 5.7032 & -3.47 \\
\hline 10 & 5.5847 & 5.5795 & 0.09 \\
\hline 11 & 7.3035 & 7.2970 & 0.09 \\
\hline 12 & 6.5919 & 6.1974 & 5.98 \\
\hline 13 & 5.5478 & 4.9612 & 10.57 \\
\hline 14 & 5.4323 & 5.2339 & 3.65 \\
\hline 15 & 5.4323 & 5.2339 & 3.65 \\
\hline 16 & 5.4323 & 5.2339 & 3.65 \\
\hline 17 & 6.0050 & 5.2671 & 12.29 \\
\hline 18 & 5.7745 & 5.5158 & 4.48 \\
\hline 19 & 5.5662 & 5.9140 & -6.25 \\
\hline 20 & 6.1174 & 5.9685 & 2.43 \\
\hline
\end{tabular}

Fig. 1 shows the effect of different constituents of the regression equation on the fatigue limit. In Fig. 1, where $A$, $B$ and $C$ represent wt.\% of Coir in the samples, wt.\% of CNT in the samples and wt.\% of Fly Ash in the samples respectively. From the Fig. 1, one can understand that the influence of CNT is maximum on the value of fatigue limit. The influence of fly ash is negligible as compared to CNT and coir.

Fig. 2 represents the surface plot between fatigue limit vs. CNT and coir. It is concluded from the Fig. 2 that adding 0.5 to $1 \%$ of CNT makes huge effect on the fatigue limit while effect of coir decreases as increase in the amount till $2 \%$. Addition of Coir helps to increase the green content of the samples but its effect on the fatigue limit is very less.

Fig. 3 illustrates the surface plot of fatigue limit vs. CNT and fly ash. Fig. 3 helps to understand the effect of both CNT and fly ash on the fatigue limit. It is understood that combination of $1 \% \mathrm{CNT}$ and $0 \%$ fly ash results in the maximum amount of the fatigue limit but increase in the wt.\% of fly ash tends to decrease the fatigue limit.

Fig. 4 explains the interaction among the coir and fly ash on fatigue limit. From Fig. 4, it is evident that the increasing fly ash and coir wt.\% increases fatigue limit till $2 \%$ of both fly ash and coir.

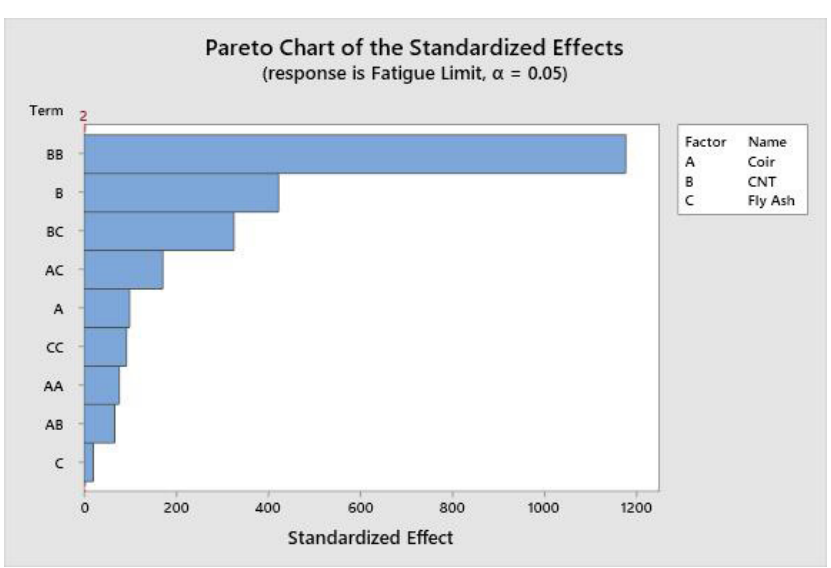

Fig. 1 Effect of constituents on fatigue limit

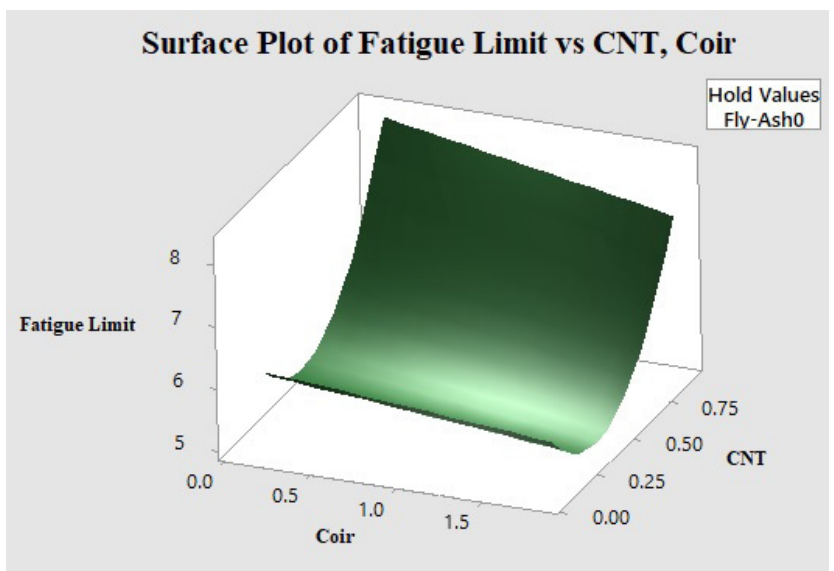

Fig. 2 Surface plot of fatigue limit vs. CNT/Coir

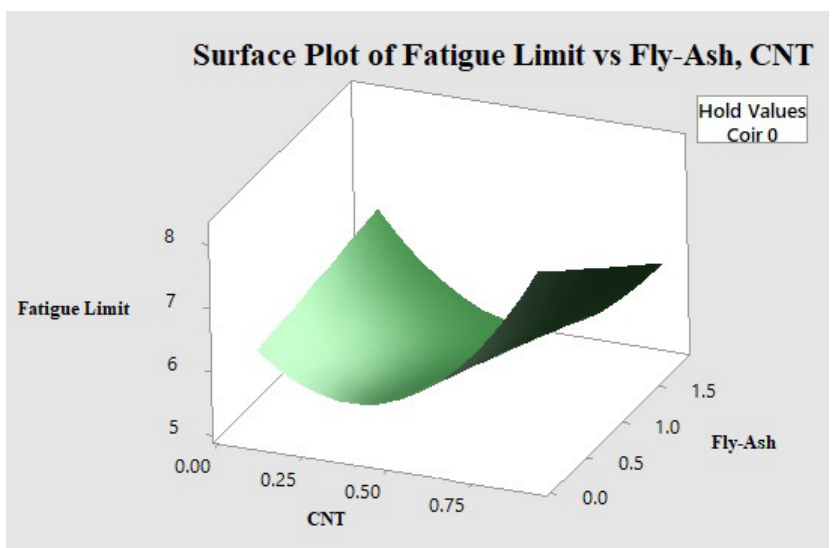

Fig. 3 Surface plot of fatigue limit vs. fly-ash, CNT

Fig. 5 presents main effect plot for fatigue limit in terms of coir, CNT and fly ash. Main effect plot shows the individual performance of the reinforcements on the fatigue limit. It is palpable from Fig. 5 that coir and fly ash increase the fatigue limit in the range of $0.5 \%$ to $1.5 \%$ whereas CNT increases the fatigue limit in the range of $0.75 \%$ to $1 \%$. Optimization of parameters is carried to find the optimum values of parameters to get maximum fatigue limit. There are two cases considered in the analysis. Tables 6 and 7 explain the optimum 


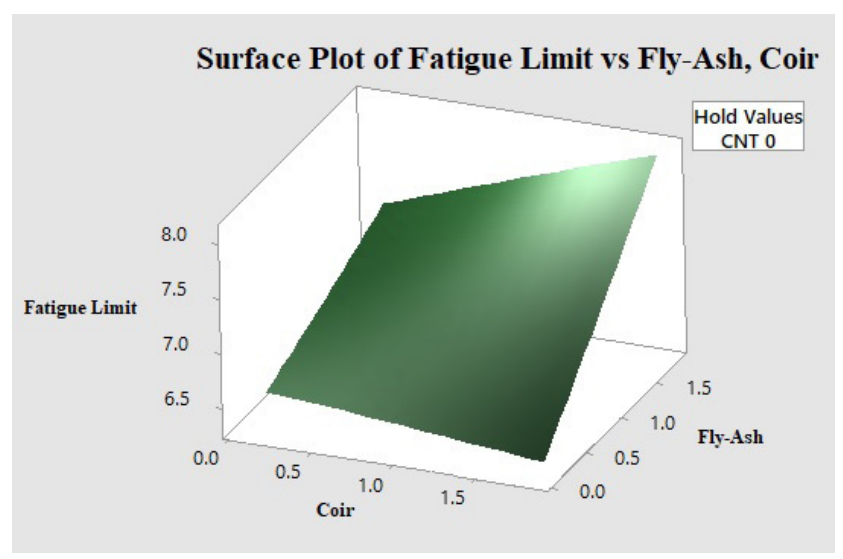

Fig. 4 Surface plot of fatigue limit vs. fly-ash, Coir

parameters and maximum value of fatigue limit. In both cases composite desirability is maintained at 1 . Among the two cases, case (I) gives maximum value of fatigue limit (8.81 MPa) with zero wt.\% of coir and fly ash. If the objective is to increase the green/waste material content in the composite, the case (II) is the right option. In that scenario, $90 \%$ of fatigue limit of case (I) is maintained with the addition of green/waste material content.

\section{Conclusion}

Fatigue limit of coir/CNT/fly ash reinforced epoxy polymer matrix composite is determined using Soderberg equation. In order to explore the influences of wt.\% of coir, CNT and fly ash on fatigue limit of polymer composite, Response Surface Methodology is employed. After the calculating fatigue limit of all samples, ANOVA is applied to understand the influences of wt.\% of coir, CNT and fly

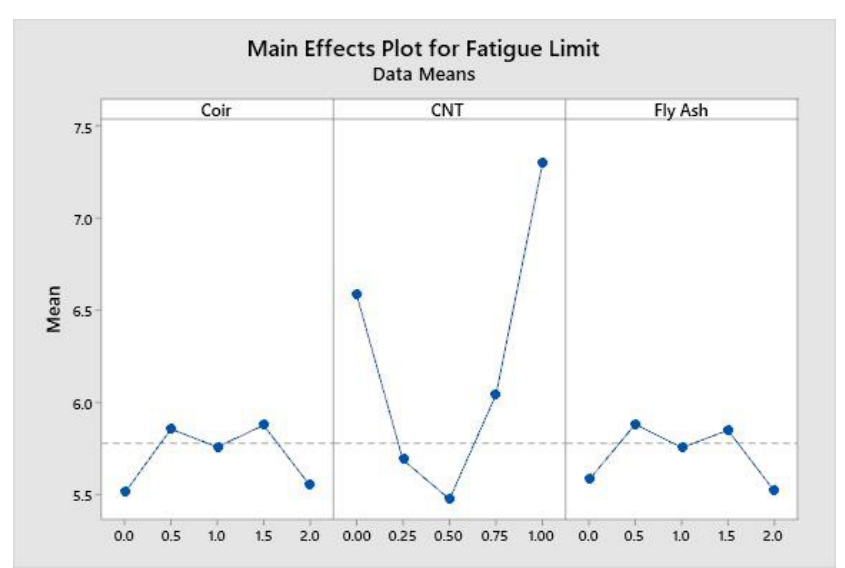

Fig. 5 Main effects plot for fatigue limit

ash on fatigue limit of polymer composite. Mean effects plot, surface plots and regression equation are obtained. Fatigue limit values, predicted using Regression equation, are in good agreement with that of Soderberg equation. Results from ANOVA analysis reveal that wt.\% of CNT has more influence than coir and fly ash. Two cases are considered in the optimization section. It is suggested from the optimization analysis to consider the case (II) as it has green/waste materials presence with $90 \%$ of fatigue limit value of case (I) which has no green/waste material presence. Combination of coir (0.55 wt.\%), CNT (1 wt.\%) and fly ash (0.55 wt.\%) gives fatigue limit of $7.84 \mathrm{MPa}$.

\section{Acknowledgement}

The project presented in this article is not financially supported by any government or private agencies.

Table 6 Parameters and solution for optimization case (I)

\begin{tabular}{|c|c|c|c|c|c|c|c|}
\hline \multicolumn{8}{|l|}{ Parameters } \\
\hline Response & \multicolumn{2}{|c|}{ Goal } & Lower & Target & Upper & Weight & Importance \\
\hline Fatigue Limit & \multicolumn{2}{|c|}{ Maximum } & 5.43225 & 7.3 & & 1 & 1 \\
\hline \multicolumn{8}{|l|}{ Solution } \\
\hline Solution & Coir & CNT & Fly Ash & Fatigue Fit & Composite Desirability & & \\
\hline 1 & 0 & 1 & 0 & 8.81 & 1 & & \\
\hline \multicolumn{8}{|c|}{ Table 7 Parameters and solution for optimization case (II) } \\
\hline \multicolumn{8}{|l|}{ Parameters } \\
\hline Response & \multicolumn{2}{|c|}{ Goal } & Lower & Target & Upper & Weight & Importance \\
\hline Fatigue Limit & \multicolumn{2}{|c|}{ Maximum } & 5.4323 & 7.301 & & 1 & 1 \\
\hline \multicolumn{8}{|l|}{ Solution } \\
\hline Solution & Coir & $\mathrm{CNT}$ & Fly Ash & Fatigue Fit & Composite Desirability & & \\
\hline 1 & 0.55 & 1 & 0.55 & 7.84 & 1 & & \\
\hline
\end{tabular}




\section{References}

[1] Pandi, S. S. A., Roja, S. Y., Jenitha, G., Alagusankareswari, K. "Experimental Study on Behavior of Coir Fibre Reinforced Concrete", International Journal of Civil Engineering and Technology, 8(2), pp. 141-147, 2017. [online] Available at: http://www.iaeme.com/IJCIET/issues.asp?JType=IJCIET\&VType $=8 \&$ IType $=2$ [Accessed: 02 March 2020]

[2] Ali, M., Chouw, N. "Experimental investigations on coconut-fibre rope tensile strength and pullout from coconut fibre reinforced concrete", Construction and Building Materials, 41, pp. 681-690, 2013.

https://doi.org/10.1016/j.conbuildmat.2012.12.052

[3] Ali, M., Liu, A., Sou, H., Chouw, N. "Mechanical and dynamic properties of coconut fibre reinforced concrete", Construction and Building Materials, 30, pp. 814-825, 2012.

https://doi.org/10.1016/j.conbuildmat.2011.12.068

[4] Yousif, B. F., Ku, H. "Suitability of using coir fiber/polymeric composite for the design of liquid storage tanks", Materials \& Design, 36, pp. 847-853, 2012.

https://doi.org/10.1016/j.matdes.2011.01.063

[5] Karthikeyan, A., Balamurugan, K. "Effect of alkali treatment and fiber length on impact behavior of coir fiber reinforced epoxy composites", Journal of Scientific \& Industrial Research, 71, pp. 627-631, 2012. [online] Available at: http://hdl.handle. net/123456789/14634 [Accessed: 13 March 2020]

[6] Fu, S.-Y., Xu, G., Mai, Y.-W. "On the elastic modulus of hybrid particle/short fiber/polymer composites", Composites Part B: Engineering, 33(4), pp. 291-299, 2002.

https://doi.org/10.1016/S1359-8368(02)00013-6

[7] Bansal, S., Ramachandran, M., Raichurkar, P. "Comparative Analysis of Bamboo using Jute and Coir Fiber Reinforced Polymeric Composites", Materials Today: Proceedings, 4(2), pp. 3182-3187, 2017.

https://doi.org/10.1016/j.matpr.2017.02.203

[8] Basiji, F., Safdari, V., Nourbakhsh, A., Pilla, S. "The effects of fiber length and fiber loading on the mechanical properties of wood-plastic (polypropylene) composites", Turkish Journal of Agriculture and Forestry, 34, pp. 191-196, 2010.

https://doi.org/10.3906/tar-0903-16

[9] Ramesh, M., Atreya, T. S. A., Aswin, U. S., Eashwar, H., Deepa, C. "Processing and Mechanical Property Evaluation of Banana Fiber Reinforced Polymer Composites", Procedia Engineering, 97, pp. 563-572, 2014. https://doi.org/10.1016/j.proeng.2014.12.284

[10] Hossain, M. R., Islam, M. A., Van Vuurea, A., Verpoest, I "Tensile Behavior of Environment Friendly Jute Epoxy Laminated Composite", Procedia Engineering, 56, pp. 782-788, 2013. https://doi.org/10.1016/j.proeng.2013.03.196

[11] Saradava, B. J., Rachchh, N. V., Misra, R. K., Roychowdhary, D. G. "Mechanical Characterization of Coir Fiber Reinforced Polymer Composite Using Red Mud as Filler", Journal of Information, Knowledge and Research in Mechanical Engineering, 2(2), pp. 472-476, 2014. [online] Available at: http://www.ejournal.aessangli.in/ASEEJournals/MECH63.pdf [Accessed: 11 March 2020]
[12] Banerjee, D., Nguyen, T., Chuang, T.-J. "Mechanical properties of single-walled carbon nanotube reinforced polymer composites with varied interphase's modulus and thickness: A finite element analysis study", Computational Materials Science, 114, pp. 209-218, 2016. https://doi.org/10.1016/j.commatsci.2015.12.026

[13] Ashrafi, B., Guan, J., Mirjalili, V., Zhang, Y., Chun, L., Hubert, P., Simard, B., Kingston, C. T., Bourne, O., Johnston, A. "Enhancement of mechanical performance of epoxy/carbon fiber laminate composites using single-walled carbon nanotubes", Composites Science and Technology, 71(13), pp. 1569-1578, 2011. https://doi.org/10.1016/j.compscitech.2011.06.015

[14] Yokozeki, T., Iwahori, Y., Ishiwata, S., Enomoto, K. "Mechanical properties of CFRP laminates manufactured from unidirectional prepregs using CSCNT-dispersed epoxy", Composites Part A: Applied Science and Manufacturing, 38(10), pp. 2121-2130, 2007. https://doi.org/10.1016/j.compositesa.2007.07.002

[15] Patil, S. L., Kale, J. N., Suman, S. "Fly Ash Concrete: A Technical Analysis for Compresssive Strength", International Journal of Advanced Engineering Research and Studies, 2(1), pp. 128-129, 2012.

[16] Chen, P., Li, J., Zhang, L. "Analysis of Mechanical Characteristics of Fly Ash Cenospheres Reinforced Epoxy Composites", Journal of Wuhan University of Technology - Materials Science Edition, 33(1), pp. 139-145, 2018.

https://doi.org/10.1007/s11595-018-1798-8

[17] Deepthi, M. V., Sharma, M., Sailaja, R. R. N., Anantha, P., Sampathkumaran, P., Seetharamu, S. "Mechanical and thermal characteristics of high density polyethylene-fly ash Cenospheres composites", Materials \& Design, 31(4), pp. 2051-2060, 2010. https://doi.org/10.1016/j.matdes.2009.10.014

[18] Nath, D. C. D., Bandyopadhyay, S., Gupta, S., Yu, A., Blackburn, D., White, C. "Surface-coated fly ash used as filler in biodegradable poly(vinyl alcohol) composite films: Part 1 - The modification process", Applied Surface Science, 256(9), pp. 2759-2763, 2010. https://doi.org/10.1016/j.apsusc.2009.11.024

[19] Mahalingam, S., Gopalan, V., Velivela, H., Pragasam, V., Prabhakaran, P., Suthenthiraveerappa, V. "Studies on shear strength of CNT/coir fibre/fly ash-reinforced epoxy polymer composites", Emerging Materials Research, 9(1), pp. 78-88, 2020. https://doi.org/10.1680/jemmr.19.00098

[20] Purohit, R., Sahu, P., Rana, R. S., Parashar, V., Sharma, S. "Analysis of Mechanical Properties of Fiber Glass-Epoxy-Fly Ash Composites", Materials Today: Proceedings, 4(2), pp. 3102-3109, 2017. https://doi.org/10.1016/j.matpr.2017.02.193

[21] Kumre, A., Rana, R. S., Purohit, R. "A Review on mechanical property of sisal glass fiber reinforced polymer composites", Materials Today: Proceedings, 4(2), pp. 3466-3476, 2017. https://doi.org/10.1016/j.matpr.2017.02.236

[22] Sunkara, S., Karthikeyan, R., Sateesh, R. "Analysis of Mechanical Properties of Polymer Based Nano Fly Ash", Journal of Innovation in Mechanical Engineering, 1(2), pp. 45-49, 2018. [online] Available at: https://api.semanticscholar.org/CorpusID:202681567 [Accessed: 25 February 2020] 
[23] D'Souza, R. O., Shettigar, Y. P., Byndoor, D. P., Sudhakar, S. S., Ahmed, N., Shetty, R. "Experimental Analysis on the Mechanical Properties of Glass-Epoxy composite with Fly ash as a filler material", IOP Conference Series: Materials Science and Engineering, 376, Article number: 012065, 2018.

https://doi.org/10.1088/1757-899X/376/1/012065

[24] Akhil, M. V., Reddy, P. S. "Experimental investigation on mechanical properties of coal ash and fly ash reinforced glass fiber polymer matrix composites", Journal of Advanced Research in Materials Science, 31(1), pp. 1-9, 2017. [online] Available at: https://api.semanticscholar.org/CorpusID: 157060238 [Accessed: 01 March 2020]

[25] Pattanaik, A., Satpathy, M. P., Mishra, S. C. "Dry sliding wear behavior of epoxy fly ash composite with Taguchi optimization", Engineering Science and Technology, an International Journal, 19(2), pp. 710-716, 2016.

https://doi.org/10.1016/j.jestch.2015.11.010

[26] Tiwari, S., Srivastava, K., Gehlot, C. L., Srivastava, D. "Studies on Mechanical and Thermal Properties of Epoxy/Fly Ash/Nanofiller Nanocomposite: A Review", International Journal of Civil Engineering and Technology, 11(2), pp. 120-139, 2020. [online] Available at: http://www.iaeme.com/ijciet/issues.asp?JType=IJCIET\&VType $=11 \& I T y p e=2$ [Accessed: 28 February 2020]

[27] Singla, M., Chawla, V. "Mechanical Properties of Epoxy Resin - Fly Ash Composite", Journal of Minerals \& Materials Characterization \& Engineering, 9(3), pp. 199-210, 2010. https://doi.org/10.4236/jmmce.2010.93017
[28] Ramakrishna, K. B. S. S., Babu, S. B., Nagaraju, B., Prasad, K. S. "Experimental Investigation on Tensile and Damping Properties of SiC and Flyash Reinforced Glass Fiber Epoxy Composites", Journal of Recent Trends in Mechanics, 1(1-3), pp. 10-19, 2016. [online] Available at: http://matjournals.in/index.php/JoRTM/article/view/925 [Accessed: 29 January 2020]

[29] Mohan Kumar, B., Sathish, S., Soundeswaran, S. "Mechanical Properties of Fly Ash filled GFRP Composite Material", International Journal on Emerging Technologies, 11(1), pp. 215-218, 2020.

[30] Gopalan, V., Hemanth, V., Logesh, M. Sivakumar, M., Vignesh, P. "Investigation of Tensile Behaviour of carbon nano tube/coir fibre/ fly ash Reinforced Epoxy polymer Matrix Composite Material", Journal of Latin American Applied Research, (December 2019) (in press).

[31] ASM International Handbook Committee "Fracture and Fatigue of Composites, Ceramics and Glasses", In: ASM Handbook, Volume 19 - Fatigue and Fracture, ASM International, Materials Park, OH, USA, Vol. 19, pp. 895-960, 1996. https://doi.org/10.31399/asm.hb.v19.9781627081931 